University of Wollongong

Research Online

Faculty of Engineering and Information

Faculty of Engineering and Information

Sciences - Papers: Part A

Sciences

$1-1-2015$

Lateral cyclic pile-soil interaction studies on a rigid model monopile

Ren-peng Chen

Zhejiang University

Yong-Xin Sun

Zheijang University

Bin Zhu

Zhejiang University, zhubin_ccea@yahoo.com.cn

Wei Dong Guo

University of Wollongong, wdguo@uow.edu.au

Follow this and additional works at: https://ro.uow.edu.au/eispapers

Part of the Engineering Commons, and the Science and Technology Studies Commons

Research Online is the open access institutional repository for the University of Wollongong. For further information contact the UOW Library: research-pubs@uow.edu.au 


\title{
Lateral cyclic pile-soil interaction studies on a rigid model monopile
}

\author{
Abstract \\ The monopile foundation of an offshore wind turbine will unavoidably suffer from long-term cyclic loading \\ during its lifetime, due to impacts from waves and wind. In this paper, a series of tests on a rigid model \\ monopile, subjected to lateral cyclic loading, were carried out in Qiantang River silt to investigate the pile- \\ soil interaction mechanism and accumulated deformation. The tests revealed that the accumulated \\ displacement is closely related to the cyclic load ratio but has no obvious relationship with the relative \\ density of the soil. In contrast, the unloading stiffness is independent of the cyclic ratio but is related to \\ the relative density of the soil. The soil around the rigid monopile under cyclic loading undergoes a \\ shearing stage during the first ten cycles, followed by the densification stage. The shearing stage \\ dominates the cyclic responses of the rigid monopile, within which the total displacement in each cycle \\ reduced obviously; the proportion of the elastic displacement to the total displacement for each cycle \\ increases from $\sim 0.5$ to 0.95 , and the soil pressures degrade to a large extent.

\section{Disciplines} \\ Engineering | Science and Technology Studies

\section{Publication Details} \\ Chen, R., Sun, Y., Zhu, B. \& Guo, W. (2015). Lateral cyclic pile-soil interaction studies on a rigid model \\ monopile. Proceedings of the Institution of Civil Engineers: Geotechnical Engineering, 168 (2), 120-130.
}


3

Ren-peng Chen ${ }^{1}$, Yong-xin $\mathrm{Sun}^{2}$, Bin $\mathrm{Zhu}^{3 *}$, Wei Dong Guo ${ }^{4}$

5

$6{ }^{1}$ Ph.D., Professor, MOE Key Laboratory of Soft Soils and Geoenvironmental

7 Engineering, Department of Civil Engineering, Zhejiang University, Hangzhou,

8 310058, China. E-mail: chenrp@zju.edu.cn.

92 Graduate student, MOE Key Laboratory of Soft Soils and Geoenvironmental 10 Engineering, Department of Civil Engineering, Zhejiang University, Hangzhou, 11310058 , China.

$12{ }^{3}$ Ph.D., Professor, corresponding author, MOE Key Laboratory of Soft Soils and 13 Geoenvironmental Engineering, Department of Civil Engineering, Zhejiang 14 University, Hangzhou, 310058, China. E-mail: binzhu@zju.edu.cn.

$15{ }^{4}$ Ph.D., Associate Professor, School of Civil, Mining and Environmental Engineering, 16 University of Wollongong NSW, 2522, Australia.

18 Number of words: 4857

19 Number of pages: 42

20 Number of figures: 17

21 Number of tables: 3 
23 Abstract: The monopile foundation of an offshore wind turbine will unavoidably

24 suffer from long-term cyclic loading during its lifetime, due to impacts from waves

25 and wind. In this paper, a series of tests on a rigid model monopile, subjected to

26 lateral cyclic loading, were carried out in Qiantang River silt to investigate the

27 pile-soil interaction mechanism and accumulated deformation. The tests revealed that

28 the accumulated displacement was closely related to the cyclic load ratio but has no

29 obvious relationship with the relative density of soil. In contrast, the unloading

30 stiffness is independent of the cyclic ratio but the relative density of soil.

31 The soil around the rigid monopile under cyclic loading undergoes a shearing

32 stage during the first 10 cycles, followed by densification. The shearing stage

33 dominates the cyclic responses of the rigid monopile, within which the total

34 displacement in each cycle reduced obviously; the proportion of the elastic

35 displacement to the total displacement for each cycle increases from $\sim 0.5$ to 0.95 , and

36 the soil pressures degrade to a large extent.

37

38 Keywords: Monopile; cyclic loading; pile-soil interaction; accumulated deformation. 


\section{Introduction}

Currently, monopiles with a diameter of 3-8 m are widely used in European and

41 Chinese offshore wind farms due to their relatively easier installation and lower cost.

42 The monopile foundations of offshore wind turbines are generally short and rigid and

43 are becoming an ideal type of foundation for offshore wind turbines located on a

44 seabed with silt or silty sand, which is the case across much of the coastal regions of

45 China.

46 During its lifetime, the monopile foundation of an offshore wind turbine is

47 unavoidably subject to long-term cyclic loads, originating from waves and wind. This

48 leads to accumulated rotation and changes in the stiffness of the monopile and

49 seriously impacts the normal operation of the offshore wind turbine. Therefore, it is

50 important to predict the deformation behaviours of the monopile under such

51 conditions. Numerical analysis and model or field tests are generally the two most

52 favourable ways used to solve the problem. Lesny \& Hinz (2007) and Achmus et al.

53 (2009) proposed new approaches to calculate the long-term cyclic behaviours of the

54 monopile in sand while also considering the cyclic responses of the soil. They also

55 combined triaxial test results of the soil with numerical calculations. These numerical

56 analyses still need further verification using model or field tests.

57 At present, it is both challenging and uneconomical to carry out full-scale model

58 tests or field tests on a monopile with a large diameter, thus model tests are commonly

59 used. Le Blanc et al. (2010) conducted a series of model tests at $1 \mathrm{~g}$ on a model 
monopile subjected to cyclic loading in sand with two different relative densities of

$614 \%$ and $38 \%$. In this study, approaches to predict the lateral accumulated rotation

62 under long-term cyclic loading and the changes in unloading stiffness of a monopile

63 foundation were presented for the first time. Roesen et al. (2011) carried out a series

64 of one-way cyclic loading tests on a pile embedded in saturated sand with a relative

65 density of $78 \%$ to $87 \%$. They concluded that the accumulated rotation of the pile

66 would stabilise after approximately 15,000 load cycles. Peng et al. (2006) and Peralta

$67 \&$ Achmus (2010) also conducted studies on the cyclic response of a monopile placed

68 in sand. In these experimental studies, test data were fitted to obtain the development

69 of pile displacement and unloading stiffness; which unfortunately are unable to fully

70 explain the mechanisms behind the accumulated deformation of a monopile. It is

71 worthwhile to mention that Cuéllar et al. $(2009,2012)$ carried out a series of

72 enlightening model tests to observe the behaviours of sand particles around a pile

73 subjected to long-term lateral cyclic loading by staining part of sand particles. The

74 study provides a detailed process of sand densification and convective cell flow of

75 sand grains during cyclic loading, as well as the characteristics and mechanisms

76 behind the pile foundation's accumulative deformation under long-term cyclic

77 loading.

Most of these studies have focused on the deformation behaviours of a pile

79 subjected to cyclic loading (including calculation formula). The pile-soil interaction

80 has not received adequate attention, but it is important and merits further study. In this 
81 paper, responses of a rigid monopile under long-term cyclic loading are determined

82 experimentally, with a particular focus on the characteristics of pile-soil interaction

83 and the mechanisms of accumulated deformation. Model tests were developed and

84 conducted at $1 \mathrm{~g}$ on a model monopile subjected to lateral cyclic loading in Qiantang

85 River silt with two different relative densities of $88 \%$ and $70 \%$.

\section{Test program}

87

88

\subsection{Test soil and preparation}

The model tests on the monopile were carried out in a barrel-shaped soil tank, $3.70 \mathrm{~m}$ in diameter and $1.70 \mathrm{~m}$ in depth, located at Zhejiang University. The schematic setup of current model tests is shown in Fig. 1.

The soil (referred to as Qiantang River Silt in this paper) used in the model tests was taken from an excavation pit near the Qiantang River in the city of Hangzhou. It consisted of $12 \%$ sand, $80 \%$ silt and less than $5 \%$ clay particles (Jia et al. 2009). The properties of the natural Qiantang River silt are shown in Table 1. Laboratory tests indicated the Qiantang river silt soil has an optimum water content of 18\% (ASTM D 698), a minimum dry density of $12.35 \mathrm{kN} / \mathrm{m}^{3}$ (ASTM D 4254), and a maximum dry density of $15.39 \mathrm{kN} / \mathrm{m}^{3}$ (ASTM D 4253). By mass controlling, the soil was poured into the tank layer by layer. Each layer was compacted to a thickness of $0.05 \mathrm{~m}$ using an NZH-type vibration machine. Before the filling of a new layer, a less than 5\% difference in soil density $\left(\sim 17.3 \mathrm{kN} / \mathrm{m}^{3}\right.$ with $\left.D_{\mathrm{r}}=88 \%\right)$ was ensured (by measuring densities of three randomly selected points in the current soil layer), and its upper 
surface was roughed. The compaction energy was doubled to achieve a relative density $D_{r}=88 \%$ against $D_{r}=70 \%$. The properties of the tested Qiantang River silt are listed in Table 2 for a $D_{r}$ of $70 \%$ and $88 \%$.

Once the filling process was complete, a suspended water tank was connected to the pipe network set at the bottom of soil tank. The water head difference allows the water 'flow' into the soil tank. The soil was subjected to saturation for $\sim 15$ days until it reaches $95 \%$ degree of saturation, which was measured using time domain reflectometry (TDR) technology (Chen et al., 2009). The water level was held at $\sim 0.02 \mathrm{~m}$ above the soil surface during the tests.

\subsection{Model pile}

Le Blanc et al. (2010) derived dimensionless equations to predict the behaviours of a field pile in cohesionless soil using model pile tests at $1 \mathrm{~g}$. Based on these equations, the current model tests selected a scaling ratio of 1:30 to simulate a monopile in the field with a diameter of $5 \mathrm{~m}$. The model, steel pipe pile has $0.165 \mathrm{~m}$ in diameter, $0.003 \mathrm{~m}$ in wall thickness, $2 \mathrm{~m}$ in length, and $0.915 \mathrm{~m}$ in embedment depth, respectively. The pile-soil relative stiffness of $E_{\mathrm{s}} L^{4} /\left(E_{\mathrm{p}} I_{\mathrm{p}}\right)$ is $4.8 \sim 388.6$ (Poulos and Hull, 1989) from flexible to rigid piles. The stiffness ratio $E_{\mathrm{s}} L^{4} /\left(E_{\mathrm{p}} I_{\mathrm{p}}\right)$ of the model piles in the silt was estimated as $3.09\left(E_{p} I_{p}=1.05 \times 10^{6} \mathrm{~N} . \mathrm{m}^{2}\right)$ for $E_{\mathrm{s}} \approx 4.64 \mathrm{MPa}$ at $D_{r}=88 \%$. The model piles are grossly regarded as rigid.

As shown in Fig. 2, the pile wall was equipped with eight total pressure 
124 of $0.2 \% \sim 0.5 \%$ ) and one pore water pressure sensor (PWP) (GE Druck PDCR81, with

125 measurement range of $0-100 \mathrm{kPa}$ to an accuracy of $0.2 \%$ ). The TPT had a sensing face

126 of $0.03 \mathrm{~m}$ in diameter. All sensors were embedded using a specially designed

127 mounting block so they were flush with the pile wall surface (see Fig. 3). Each TPT

128 and PWP was glued into a titanium case and placed in an acetyl copolymer mounting

129 block (Bond et al., 1991). To install the TPT or PWP, a hole was created at the

130 intended position on the model pile and then the base was welded together with the

131 pile. Next, boltholes were created on the base to install the sensors. The surfaces of

132 the sensors were carefully installed so they were flush with the surface of the pile wall

133 and the presence of the sensors would not affect the pile-soil interaction during

134 loading. Finally, sensor wires were directed from the inside of the closed model pile to

135 the outside. The model pile was jacked into the soil (via a long-range hydraulic jack)

136 at a rate of $0.01 \mathrm{~m} / \mathrm{min}$. After installation, a 24-hour pause was needed before

137 applying any loads so as to reduce the impact of pile driving on the bearing capacity

138 and deformation of the model pile. After finishing a test, the pile was extracted,

139 replaced with an un-instrumented 'dummy' pile and the instrumented pile was

140 re-installed at a new location (with a distance larger than $7 D$ to minimise the impact

141 among the tested positions) for the next test.

\subsection{Cyclic loading device}

144 A mechanical load rig, originally developed by Rovere (2004), has been 
145 successfully used in previous studies to apply cyclic loads to a model pile (Le Blanc 146 et al., 2010) and a model caisson foundation (Zhu et al., 2013). In this paper, an 147 improved loading device is presented, as shown in Fig. 4. It consists of a supporting 148 base, a lever and a balance beam with a driving motor fixed to it. The major 149 components and features are as follows: First, the loading device is a separate part 150 that can be placed at random. Second, a blade on the balance beam is placed in a 151 blade slot, which is attached to the supporting base (see Fig. 4a). The blade and the 152 blade slot make up a specific pivot, which greatly reduces the friction between the 153 balance beam and the supporting base, and also makes the balance beam very 154 sensitive to an unbalanced force. Third, a moveable turning wheel is used to adjust 155 length of the wire rope and ensures the balance beam stays horizontal even when there 156 is accumulated rotation of the foundation. This way, the magnitude of the cyclic load 157 remains stable. A motor with a rotational frequency of $0.067 \mathrm{~Hz}$ is fixed to the end of the

159 balance beam. The lever (with a length of $l_{\mathrm{a}}$ and a mass of $m$ ) is driven by the motor, 160 which causes the mass $\mathrm{M}_{1}$ (with a quality of $m_{1}$ ) to move in a uniform circular motion. 161 As a result, the moment at the pivot (caused by $\mathrm{M}_{1}$ ) changes periodically, and 162 generates a sinusoidal force $F$. The loading device provides stable and long-term 163 sinusoidal cyclic loading. Assembling different combinations of $m_{1}, m_{0}$ and $l$ (see Fig. 164 4) allows different magnitudes of cyclic loads (up to $700 \mathrm{~N}$ ) to be applied. 
167

168

169

170

171 rigid pile embedded in cohesionless soil may exhibit work behaviour, which renders

172 difficulty in determining failure point (thus $M_{\mathrm{R}}$ ) at the load-displacement curve. The

$173 M_{R}$ is taken as the moment at a pile-head displacement (at mudline) of $0.1 D$ (Cuéllar,

$1742011)$. In this manner, the ultimate capacities were estimated as $778 \mathrm{~N}\left(D_{r}=88 \%\right)$ and

$175463 \mathrm{~N}(70 \%)$, respectively from the load-displacement curves of the model pile in

176 Qiantang River silt (of Tests 7 and 8 under monotonic loading, see Fig. 5). In the

177 current one way $\left(\zeta_{c}=0\right)$ cyclic loading tests, the cyclic load ratios $\zeta_{b}$ were selected as

$1780.39,0.3,0.23$ for $D_{r}=88 \%$ silt and $0.43,0.34,0.25$ for $D_{r}=70 \%$ silt. The loading

179 eccentricity of tests was taken as $e=6 D$. The test program is listed in Table 3 .

180 measurement range of $0-2000 \mathrm{~N}$ to an accuracy of $0.25 \%$ ) was used to measure the

Four LVDTs (HCD 5000, with measurement range of 0-0.254 $\mathrm{m}$ to an accuracy

of $0.2 \%$ ) were installed on the pile to measure the instant horizontal displacement at heights (above the mudline) of $0.025,0.165(=1 D), 0.495(=3 D)$ and $0.99 \mathrm{~m}(=5 D)$, as shown in Fig. 1. In particular in Tests 4, 5 and 6, an LVDT (1000DC-SE200, with measurement range of $0-0.0254 \mathrm{~m}$ to accuracy of $0.12 \%$ ) was employed to measure the vertical displacement of the soil around the pile. A load cell (BK-1B, applied cyclic load. The test data were continuously collected by a FLUKE data 
188

189

190

191

192

193

194

195

196

197

198

199

200

201

202

203

204

205

206

207

208

collection system with a sampling frequency of $2 \mathrm{~Hz}$.

\section{Deformation behaviours of the rigid monopile and soil}

\subsection{Lateral displacement of the model pile}

Displacement of the pile is essentially due to the deformation of the surrounding soil, which consists of plastic displacement $d_{\mathrm{p}}$ and elastic displacement $d_{\mathrm{e}}$ from a loading cycle. As shown in Fig. 6, the total displacement $\left(d_{N \mathrm{p}}+d_{N \mathrm{e}}\right)$ and the elastic displacement $d_{N \mathrm{e}}$ of the pile generated in the $N$-th cycle are expressed as:

$$
\left(d_{N p}+d_{N e}\right)=D_{(N) \max }-D_{(N-1) \min }
$$

$$
d_{N e}=D_{(N) \max }-D_{(N) \min }
$$

where $D_{(N) \max }$ is the peak displacement of the pile in the $N^{\text {th }}$ cycle, $D_{(N) \min }$ is the residual displacement of the pile after $N$ cycles, and $D_{(N-1) \min }$ is the residual displacement of the pile after $(N-1)$ cycles.

\subsubsection{Residual and peak displacement}

The load-displacement curves from Test 1 (under cyclic loading) and Test 8 (under monotonic loading) are presented in Fig. 7. To improve clarity, the curves are only provided for the 1-15th cycles, 100-115th cycles, 1000-1015th cycles and 10000-10015th cycles. The figure indicates the lateral displacement of the pile increases with the loading cycles. The stiffness of the pile in the first cycle is slightly larger than that of the monotonic loading test.

A Matlab program was written to present the test data (collected by FLUKE data 
209 collection system) by number of cycles rather than by time. The cyclic load had a

210 period of $15 \mathrm{~s}$ and changed sinusoidally with time. Each period, the program picked

211 up the maximum and minimum load values, the displacement, soil pressures and the 212 pore water pressures.

213 Figure $8(\mathrm{a})$ and (b) shows the residual displacement $D_{N \min }$ and the peak 214 displacement $D_{N \max }$ (of the pile at the loading point) of each cycle with the number of 215 cycles $N$ for Tests $1-6$. It shows a linear relationship between $D_{N \min }$ and $\log (N)$, and 216 between $D_{N \max }$ and $\log (N)$; The first 10 cycles induce $55 \%-60 \%$ the lateral 217 displacement $D_{N \max }$ at the $5000^{\text {th }}$ cycle.

\subsubsection{Accumulated rotation}

The residual accumulated rotation is investigated. This is different from the

220 studies of Le Blanc et al. (2010) and Zhu et al. (2013) on the peak accumulated

221 rotation, and use of the ratio of $\left(\theta_{N p}-\theta_{0}\right) / \theta_{s}\left(\theta_{\mathrm{s}}\right.$ is the rotation induced in a static

222 test at a load equivalent to the maximum cyclic load), for a monopile and a

223 mono-caisson, respectively. Similar to Fig. 8(a), the non-dimensional residual 224 accumulated rotation values (Le Blanc et al., (2010)) of the model pile subjected to 225 one-way lateral cyclic loading vary also approximately linearly with $\log (N)$ :

$$
\tilde{t}_{N r} \ldots \ldots(N)
$$

227 In which $A$ is a constant. As shown in Fig. 9, $A$ is closely related to the cyclic load

228 ratio $\zeta_{\mathrm{b}}$ and seems to have no obvious relationship with the relative density of the soil.

\section{3.1.3 Displacement of model pile in each cycle}


231 cycle of Tests $1-6$ is plotted against the number of cycles in Fig. 10. The total 232 displacement $\left(d_{N \mathrm{p}}+d_{N \mathrm{e}}\right)$ reduces by more than $50 \%$ over the first 10 cycles. 233 Subsequently, it reduces slowly and tends to stabilise. The lateral deformation of the 234 monopile is dominated by the first 10 cycles.

235 Figure 11 shows the proportion ratio of the elastic displacement to the total 236 displacement $\left[d_{\mathrm{Ne}} /\left(d_{\mathrm{Np}}+d_{\mathrm{Ne}}\right)\right]$ for each cycle of Test 1 . It starts at 0.5 (at $N=1$ ) and 237 increases rapidly to 0.95 (at $N=10$ ). Afterwards, the value slowly increases with the 238 number of cycles and approaches unity. The model pile mainly undergoes elastic 239 deformation. The first 10 cycles are associated with shear deformation, afterwards 240 additional deformation is caused by densification of the cohesionless soil surrounding 241 the pile. The densification renders the load-displacement curve a tapering cyclic 242 hysteresis loop (see Fig. 7).

\subsection{Unloading stiffness}

An unloading stiffness $k(=M / \theta)$ is the ratio of the applied cyclic moment $(M)$ at

246 ground level to the pile rotation $(\theta)$ in a cycle of the unloading phase. It is recast into 247 non-dimensional unloading stiffness $\tilde{i} \quad \ldots-{ }^{2} D \sqrt{p_{a} \gamma^{\prime}}$ by Le Blanc et al. (2010), 248 in which $L$ is penetration depth of pile, $D$ is pile diameter, $p_{\mathrm{a}}$ is the atmospheric 249 pressure, and $\gamma^{\prime}$ is effective unit weight. The non-dimensional unloading stiffness $250\left(\tilde{I}_{\nu_{N}}\right)$ of Tests $1-6$ was obtained and is plotted in Fig. 12, as a function of $\log (N)$. It 
251 reduces in the first 10 cycles, and increases subsequently with the number of cycles.

252 For instance, the increase is $20 \%$ to $30 \%$ after 5000 cycles. The non-dimensional 253 unloading stiffness $\left(\tilde{i}_{{ }_{N}}\right)$ of the model piles after $\mathrm{N}$ cycles can be approximated by

255 where ${\tilde{i_{10}}}_{10}$ is the non-dimensional unloading stiffness after 10 cycles of loading. As a 256 result of the decline in unloading stiffness during the first 10 cycles being less than $2575 \%$, the value of ${\tilde{i_{10}}}_{10}$ can be simplified and approximated as ${\tilde{i_{1}}}_{1}$. The constant $B$ was 258 obtained by best fit of the non-dimensional unloading stiffness in Tests $1-6$, and is 259 shown in Fig. 13. The constant $B$ has the same meaning of dimensionless constant $A_{\mathrm{k}}$

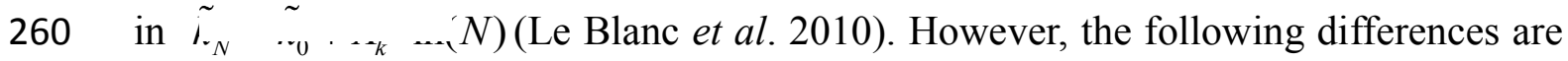
261 noted: (1) the current $B(=12.5)$ is $30 \%$ higher than $A_{\mathrm{k}}=8.02 ;(2) A_{\mathrm{k}}$ is independent of 262 both relative density and load characteristics, but the $B$ is closely related to the soil 263 relative density and has no obvious relationship with the cyclic ratio $\zeta_{\mathrm{b}}$ (see Fig. 13)

\subsection{Vertical displacement of the soil surface in front of the pile}

The vertically placed LVDT, located $0.05 \mathrm{~m}$ in front of the model pile, detected

266 the soil vertical displacement during the cyclic loading for Tests 4- 6, as shown in Fig.

267 14. There is an uplift of the soil during the first dozens of cycles, indicating that the 268 soil shearing deformation could contain soil dilatancy. Subsequently, the soil in front 269 of the pile tended to subside, or reduce in volume, which renders increase in 270 unloading stiffness (soil densification), as shown in Fig. 12. 


\section{Pile-soil interaction of the rigid model pile}

273

274

275

276

277 water pressure increases and decreases sinusoidally between $0 \mathrm{kPa}$ and $3 \mathrm{kPa}$. During

291 the test, the peak pore water pressure stays at $3 \mathrm{kPa}$ with $\sim 10 \%$ fluctuation. This 292

\subsection{On-pile pressures}

On-pile soil pressures of the model test are measured by the eight TPTs during cyclic loading. In Test 1, for example, the soil pressures in each cycle are plotted in Fig. 15 for increasing number of cycles. As with the total displacement and unloading stiffness, the soil pressures reduce largely in the first 10 cycles.

The model pile rotates rigidly about a centre with zero displacement. The soil above the centre is subjected to passive resistance and below to active resistance. TPTs 7 and 8 are located at the side opposite the loading direction, $0.7 \mathrm{~m}$ and $0.78 \mathrm{~m}$ below the soil surface, respectively. At cyclic ratios of 0.4 and 0.3 , the pressure values of TPT 7 are plotted in Fig. 16 as functions of the cyclic load. They increase with an increasing load, and TPT 7 is in the active zone (above the rotational centre). In contrast, little change in the pressures of TPT 8 with increasing load is noted, and TPT 8 must be close to the rotational centre, which is approximately 0.8 times the pile embedment.

The pore water pressure transducer PWP was located at $0.215 \mathrm{~m}$ below the soil surface at which the hydrostatic pressure was $2.3 \mathrm{kPa}[=(0.215+0.02) \times 9.8]$. Fig. 17 shows the measured water pressure of PWP in Test 1 during cyclic loading. The pore suggests that no excess pore-water pressure accumulated during cyclic loading at the 
depth of the transducer.

\subsection{Behaviours of nearby soil under cyclic loading}

Cuéllar et al. (2009) shows that the sand surrounding a rather flexible pile undergoes densification phase and the convection-dominated phase during long-term cyclic loading. In the densification phase, grain rearrangement and reduction of inter-granular voids takes place and is characterised by a progressive subsidence of the soil surface surrounding the pile. Once the soil subsides to a rather constant depth, the second phase starts.

The surrounding soil in the current tests exhibits shearing deformation in the first

10 cycles and densification in the subsequent cycles. The associated pile response has

304 been discussed before, as highlighted herein. During the shearing deformation, (1) the

305 plastic displacement $d_{\mathrm{p}}$ of the soil accounts for a large proportion of the total 306 displacement in a given cycle (see Fig. 11); (2) The unloading stiffness of the pile 307 decreases (see Fig. 12). (3) The soil dilatancy (associated an increase in the soil 308 volume) occurs, which, together with the lateral movement, may cause the uplift of 309 the soil surface in front of the pile (see Fig. 14). As for the densification stage, a 310 reduction of inter-granular voids seems to have occurred, as the elastic displacement $311 d_{\mathrm{e}}$ of the soil also accounts for a large proportion of the total displacement in a cycle 312 (see Fig. 11), and the unloading stiffness increases (see Fig. 12). 


\section{Limitations}

This paper has made a preliminary evaluation of pile-soil interaction mechanisms and accumulated deformation for a rigid model monopile under lateral cyclic loading

317 in Qiantang River silt. There are a few limitations to this study. The model tests were 318 conducted at $1 \mathrm{~g}$ condition and based on the dimensionless equations for scaling of 319 laboratory tests. These dimensionless equations in turn were based on the ultimate 320 limit state of the sand. Their applicability to soil at an elastic-plastic state is uncertain.

321 The cohesionless soil exhibits dilatancy at low stress levels (e.g. in laboratory tests at $3221 \mathrm{~g}$ ) (Guo and Qin, 2010), which may not occur in the field. As a result, the 323 cohesionless soil in model tests may be associated with a higher peak friction angle 324 than the soil with the same relative density present in the field (Le Blanc et al., 2010).

\section{Conclusions}

In this paper, six model tests were carried out on an instrumented rigid model

328 pile in Qiantang River silt that was subjected to lateral cyclic loading with different 329 cyclic ratios for $5000-10000$ cycles. The main conclusions drawn are as follows:

330 (1) The accumulated displacement is closely related to the cyclic load ratio and 331 has no obvious relationship with soil density. In contrast, the unloading stiffness is 332 independent of the cyclic ratio but is related to the relative density of the soil. The 333 peak and residual accumulated displacements increase linearly with the logarithm of 334 the number of cycles. 
336 the pile embedment during cyclic loading.

337 (3) There was generally a slight degradation of the peak value of on-pile soil 338 pressure in the first 10 cycles, which tends to be invariable afterwards.

339 (4) The first 10 cycles (of shearing stage) have a great influence on the cyclic 340 responses of the rigid monopile under cyclic loading, rather than the subsequent 341 densification stage.

\section{Acknowledgements}

The authors would like to acknowledge funding and financial support from the

345 National Natural Science Foundation of China (research grant: 51179169, 51225804, 346 and U1234204).

\section{$348 \quad$ References}

349 ASTM (2006) D 4253: Standard Test Methods for Maximum Index Density and Unit 350 Weight of Soils Using a Vibratory Table. ASTM International, West 351 Conshohocken, PA, USA.

352 ASTM (2006) D 4254: Standard Test Methods for Minimum Index Density and Unit 353 Weight of Soils and Calculation of Relative Density. ASTM International, West 354 Conshohocken, PA, USA. 

Characteristics of Soil Using Standard Effort (12 $400 \mathrm{ft}-\mathrm{lbf} / \mathrm{ft} 3(600 \mathrm{kN}-\mathrm{m} / \mathrm{m} 3))$. ASTM International, West Conshohocken, PA, USA.

Bond AJ, Jardine RJ and Dalton JCP (1991) Design and performance of the Imperial College instrumented pile. Geotechnical Testing Journal 14(4): 413-424.

Chen RP, Xu W and Chen YM (2009) Measuring Dielectric Constant in Highly Conductive Soils Based on Surface Reflection Coefficients. Journal of Geotechnical and Geoenvironmental Engineering, ASCE 135(12): 1883-1891.

Cuéllar P (2011) Pile foundations for offshore wind turbines: Numerical and experimental investigations on the behaviour under short-term and long-term cyclic loading. Ph.D. Thesis, Technical University, Berlin.

Cuéllar P, Baeßler M and Rücker W (2009) Ratcheting convective cells of sand grains

368 Cuéllar P, Georgi S, Baeßler M and Rücker W (2012) On the quasi-static granular 369 convective flow and sand densification around pile foundations under cyclic lateral loading. Granular Matter 14(1): 11-25.

371 Guo, W. D. and Qin, H. Y. (2010). "Thrust and bending moment of rigid piles 372 subjected to moving soil.” Canadian Geotechnical Journal, 47(2), 180-196.

373 Jia GW, Zhan LT, Chen YM and Fredlund DG (2009) Performance of a large-scale 374 slope model subjected to rising and lowering water levels. Engineering Geology 106(1-2): 92-103. 
376 LeBlanc C, Houlsby GT and Byrne BW (2010) Response of stiff piles in sand to 377 long-term cyclic lateral loading. Géotechnique 60(2): 79-90.

378 Peng JR, Clarke B and Rouainia M (2006) A device for cyclic lateral loaded model 379 piles. Geotechnical Testing Journal 29(4): 1-7.

380 Peralta P and Achmus M (2010) An Experimental Investigation of Piles in Sand 381 Subjected to Cyclic Lateral Loads. Proceedings of the 7th International 382 Conference on Physical Modelling in Geotechnics. Zurich, Switzerland, pp. $383 \quad 985-990$.

384 Poulos $\mathrm{H}$ and Hull $\mathrm{T}$ (1989) The role of analytical geomechanics in foundation 385 engineering. In Foundation Engineering: Current Principles and Practices, ASCE, New York, vol. 2, pp. 1578-1606.

387 Rovere M. (2004) Cyclic loading test machine for caisson suction foundations. 388 Politecnico di Milano, Milan, Italy.

389 Roesen HR, Andersen LV, Ibsen LB and Foglia A (2011) Experimental Setup for 390 Cyclic Lateral Loading of Monopiles in Sand. Department of Civil Engineering, 391 Aalborg University, Aalborg, Denmark.

392 Zhu B, Byrne BW and Houlsby GT (2013) Long term lateral cyclic response of 393 suction caisson foundations in sand. Journal of Geotechnical and 394 Geoenvironmental Engineering, ASCE 139(1): 73-83. 
fitting parameter for non-dimensional rotation of pile

$399 A_{k}$ dimensionless constant

$400 \quad B$

fitting parameter for non-dimensional unloading stiffness of pile

$401 \quad C_{\mathrm{c}}$ coefficient of curvature

$402 C_{\mathrm{u}}$ uniformity coefficient

$403 c^{\prime}$

effective cohesion

$404 \quad D$

pile diameter

$405 \quad D_{\mathrm{r}}$

relative density

406

$d_{\mathrm{e}}, d_{p}, d_{N \mathrm{p}}, d_{N \mathrm{~N}}, \quad$ deformation parameters

407

$D_{(N) \max }, D_{(N) \min } \quad$ maximum and minimum deformation parameters

$408 d_{50}$

average grain size

$409 d_{\mathrm{s}}$

specific gravity

$410 \quad E_{\mathrm{c}}$

compressive modulus

$411 \quad E_{\mathrm{p}}$

elastic modulus of pile

$412 \quad E_{\mathrm{s}}$

elastic modulus of soil

$413 \quad e$

load eccentricity

$414 \quad F$

force

$415 g$

gravitational acceleration

$416 \quad I_{\mathrm{p}}$

moment of inertia of pile

$417 \quad k$

unloading stiffness

$418 \tilde{i_{1}}, \tilde{I}_{v},{\tilde{I_{1}}}_{1}, \tilde{I}_{10}, \tilde{r}_{N}$ normalized unloading stiffness

$419 L \quad$ embedded depth of pile

$420 \quad l, l_{0}, l_{\mathrm{a}}, l_{\mathrm{c}} \quad$ load device dimensions

$421 M, M_{\max }, M_{\min } \quad$ moment at ground surface

$422 \quad M_{\mathrm{R}}$

static moment resistance of pile

$423 \quad m, m_{0}, m_{1}$

load device masses

$424 \quad N$

number of load cycles 


\begin{tabular}{|c|c|c|}
\hline 425 & $\mathrm{P}_{\mathrm{a}}$ & atmospheric pressure \\
\hline 426 & $\gamma^{\prime}$ & effective unit weight \\
\hline 427 & $\gamma_{\text {sat }}$ & Saturated unit weight \\
\hline 428 & $\zeta_{b}, \zeta_{c}$ & load characteristic parameters \\
\hline 429 & $w$ & natural water content \\
\hline 430 & $w_{\mathrm{L}}$ & liquid limit \\
\hline 431 & $w_{\mathrm{op}}$ & optimum water content \\
\hline 432 & $w_{\mathrm{P}}$ & plastic limit \\
\hline 433 & $\mu$ & poisson's ratio \\
\hline 434 & $\varphi^{\prime}$ & effective internal friction angle \\
\hline 435 & $\theta$ & pile rotation \\
\hline 436 & $\theta_{0}$ & pile rotation in the first cycle \\
\hline 437 & $\theta_{\mathrm{s}}$ & static pile rotation \\
\hline 438 & $\theta_{\mathrm{Np}}$ & peak accumulated rotation in $N$ th cycle \\
\hline 439 & $\tilde{t}_{N r}$ & non-dimensional residual accumulated rotation in $N$ th cycle \\
\hline \multicolumn{3}{|l|}{440} \\
\hline 441 & & \\
\hline
\end{tabular}




\section{List of captions}

444 Tables

445 Table 1. Parameters of natural Qiantang River silt

446 Table 2. Parameters of tested Qiantang River silt

447 Table 3. Test program

$448 \quad$ Figures

449 Fig. 1. Schematic setup of the model tests

450 Fig. 2. Model pile and on-pile transducers

451 Fig. 3. Connection between the transducers and the model pile

452 Fig. 4. The cyclic loading device

453 Fig. 5. Load-displacement curves of Tests 7 and 8

454 Fig. 6. Schematic drawing of the lateral displacement of pile

455 Fig. 7. Load-displacement curves of Tests 1 and 8

456 Fig. 8. Measured residual and peak accumulated displacement of the pile

457 Fig. 9. Values of $A$

458 Fig. 10. Measured total displacement of the pile in each cycle

459 Fig. 11. Proportion of elastic displacement to total displacement in each cycle

460 Fig. 12. Non-dimensional unloading stiffness of the pile

461 Fig. 13. Values of $B$

462 Fig. 14.Vertical displacement of the soil surface in front of the pile

463 Fig. 15. Measured on-pile soil pressures as a function of the number of cycles (Test 1) 
464 Fig. 16. Measured on-pile soil pressures of TPTs 7 and 8

465 Fig. 17. Measured pore water pressure (Test 1)

466 


\section{Tables and Figures}

469

Table 1. Properties of natural Qiantang River silt

470

\begin{tabular}{cccccccc}
\hline $\begin{array}{c}\text { Specific } \\
\text { gravity }\end{array}$ & $\begin{array}{c}\text { Natural } \\
\text { water content }\end{array}$ & $\begin{array}{c}\text { Optimum } \\
\text { water }\end{array}$ & $\begin{array}{c}\text { Plastic } \\
\text { limit }\end{array}$ & $\begin{array}{c}\text { Liquid } \\
\text { limit }\end{array}$ & $\begin{array}{c}\text { Average } \\
\text { grain }\end{array}$ & $\begin{array}{c}\text { Uniformity } \\
\text { coefficient }\end{array}$ & $\begin{array}{c}\text { Coefficient } \\
\text { of curvature }\end{array}$ \\
& $w(\%)$ & $\begin{array}{c}w_{s} \\
w_{\mathrm{op}}(\%)\end{array}$ & $\begin{array}{c}w_{\mathrm{P}} \\
(\%)\end{array}$ & $w_{\mathrm{L}}(\%)$ & $\begin{array}{c}\text { size } \\
d_{50}(\mathrm{~mm})\end{array}$ & $C_{\mathrm{u}}$ & $C_{\mathrm{c}}$ \\
\hline 2.69 & 13 & 18 & 22.6 & 31.7 & 0.0328 & 2.48 & 1.35 \\
\hline
\end{tabular}

471

472 
474

\begin{tabular}{ccccccccc}
\hline \multirow{2}{*}{ No. } & $\begin{array}{c}\text { Saturated unit } \\
\text { weight }\left(\mathrm{kN} / \mathrm{m}^{3}\right)\end{array}$ & $\begin{array}{c}\text { Relative } \\
\text { density } \\
D_{r}(\%)\end{array}$ & $\begin{array}{c}\text { Effective internal } \\
\text { friction angle }\left({ }^{\circ}\right)\end{array}$ & $\begin{array}{c}\text { Effective } \\
\text { cohesion } \\
(\mathrm{kPa})\end{array}$ & $\begin{array}{c}\text { Compressive } \\
\text { modulus } \\
(\mathrm{MPa})\end{array}$ & $\begin{array}{c}\text { Poisson's } \\
\text { ratio }\end{array}$ \\
\hline 1 & 19.1 & 88 & 41.5 & 35.5 & 0 & 6.25 & 0.28 \\
\hline 2 & 18.8 & 70 & 37.4 & 35.5 & 0 & 5.35 & 0.30 \\
\hline
\end{tabular}

475 Note: The cohesion and friction angle and Poisson's ratio of the samples were obtained by triaxial tests (CD) with 476 confining pressures of 20,40 and $80 \mathrm{kPa}$, respectively.

477 The compressive modulus was obtained through uniaxial confined compression tests with compressive 478 stress between $0-12.5 \mathrm{kPa}$.

479 
Table 3. Test program

482

\begin{tabular}{ccccc}
\hline No. & $\begin{array}{c}\text { Relative } \\
\text { density of silt } D_{r}\end{array}$ & $\begin{array}{c}\text { Height of lateral } \\
\text { loading } e\end{array}$ & Cyclic ratio $\zeta_{b}$ & $\begin{array}{c}\text { Number of } \\
\text { cycles } N\end{array}$ \\
\hline Test 1 & $88 \%$ & $6 D$ & 0.39 & 10015 \\
Test 2 & $88 \%$ & $6 D$ & 0.30 & 5000 \\
Test 3 & $88 \%$ & $6 D$ & 0.23 & 5000 \\
Test 4 & $70 \%$ & $6 D$ & 0.43 & 5000 \\
Test 5 & $70 \%$ & $6 D$ & 0.34 & 5000 \\
Test 6 & $70 \%$ & $6 D$ & 0.25 & 5000 \\
Test 7 & $70 \%$ & $6 D$ & Monotonic & - \\
Test 8 & $88 \%$ & $6 D$ & Monotonic & - \\
\hline
\end{tabular}

483

484 


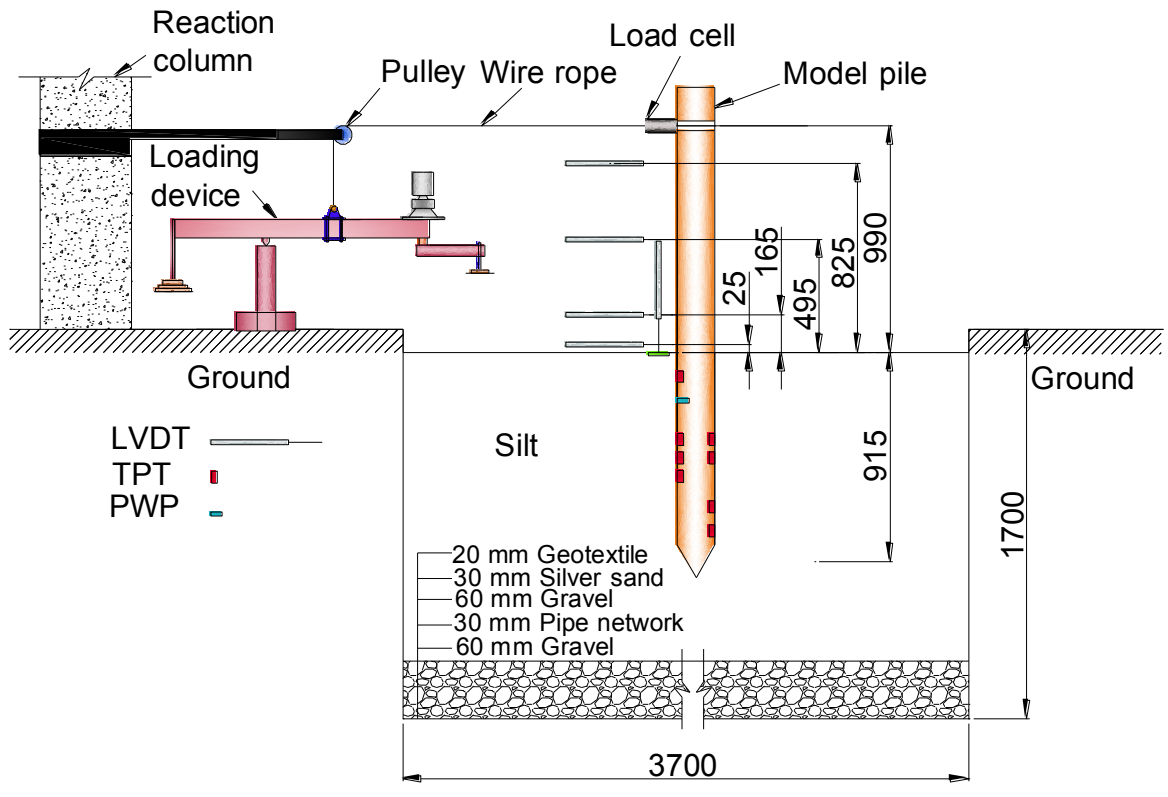

Fig. 1. Schematic setup of the model tests (unit: $\mathrm{mm}$ ) 


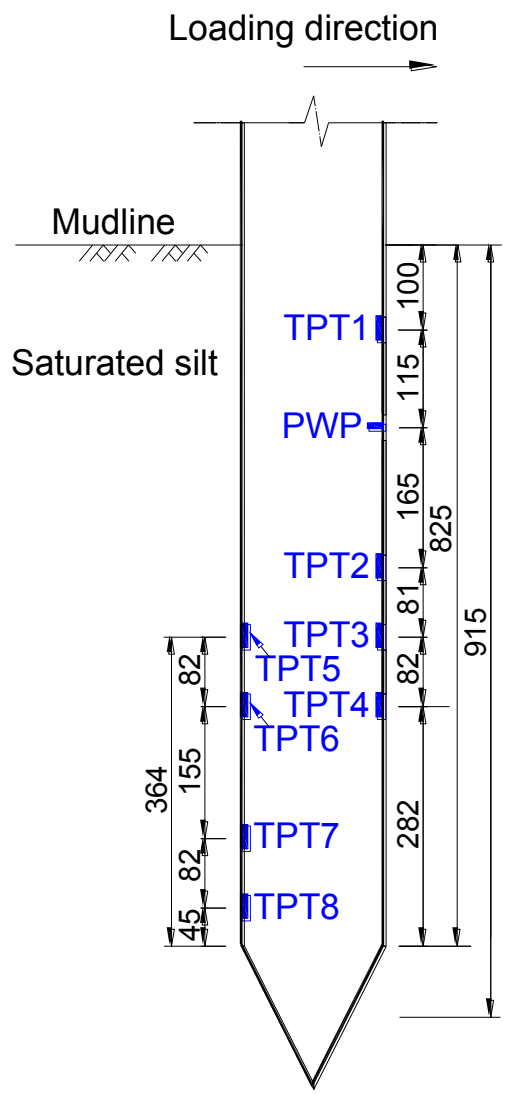

492

493

(a) Schematic diagram (Unit: $\mathrm{mm}$ )

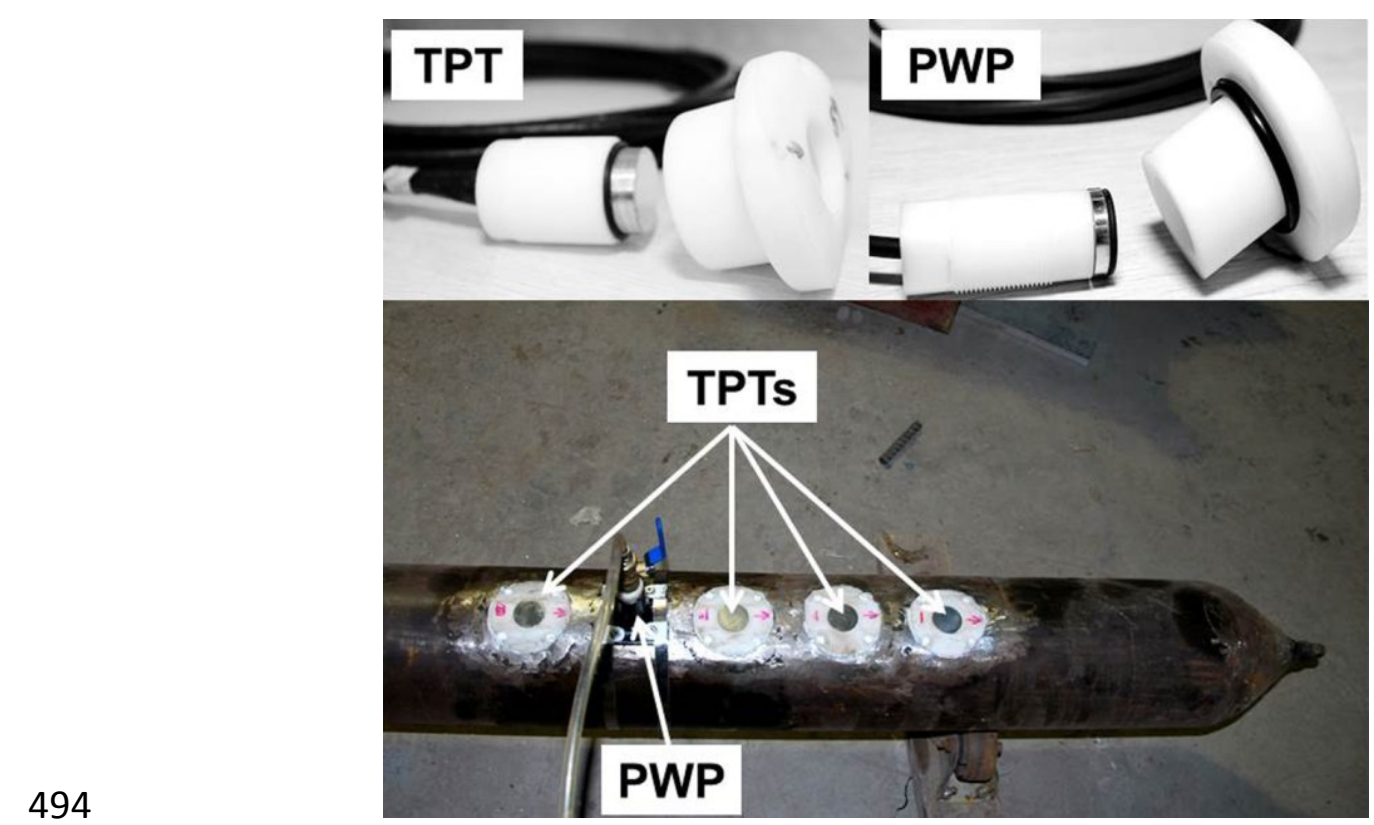

(b) Physical diagram

Fig. 2. Model pile and on-pile transducers 
498

499

500

501

502

503

504

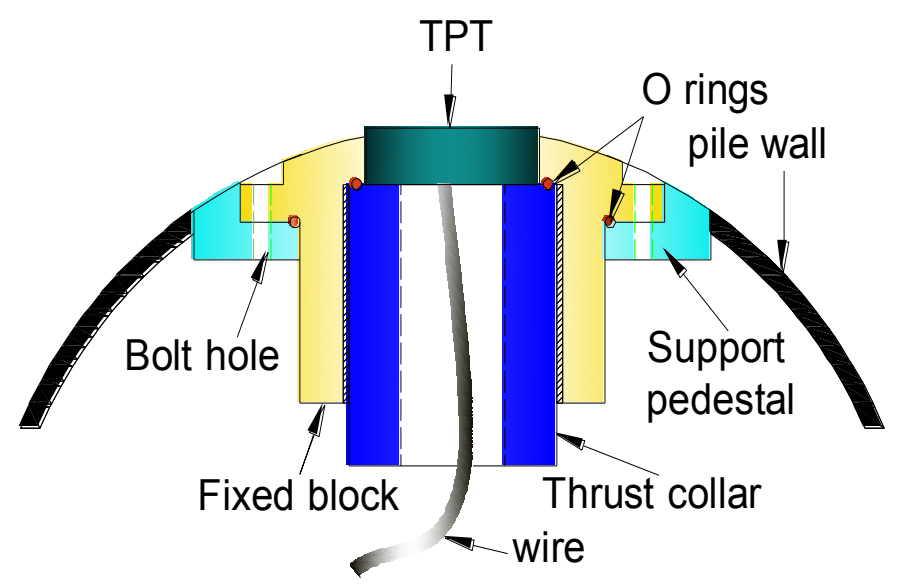

(a) TPT

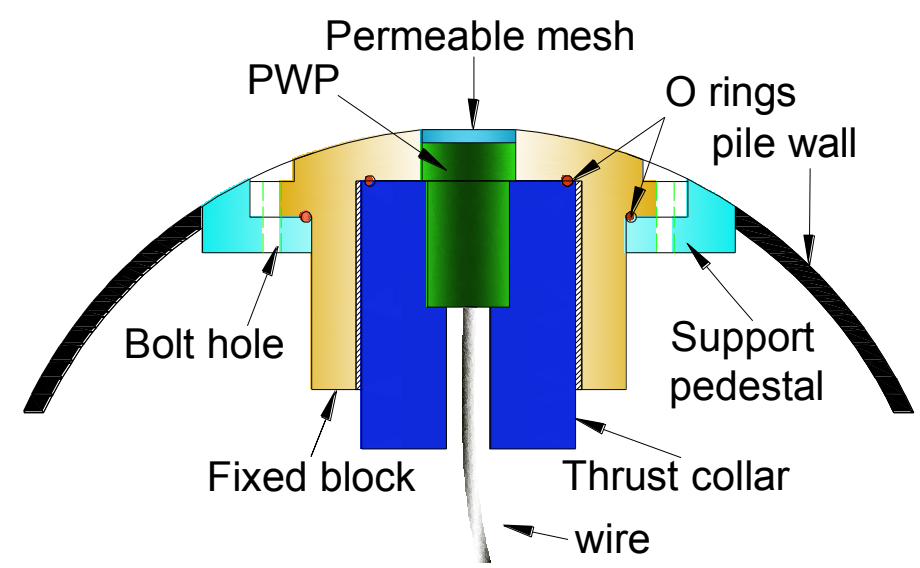

(b) PWP

Fig. 3. Connection between transducers and model pile 


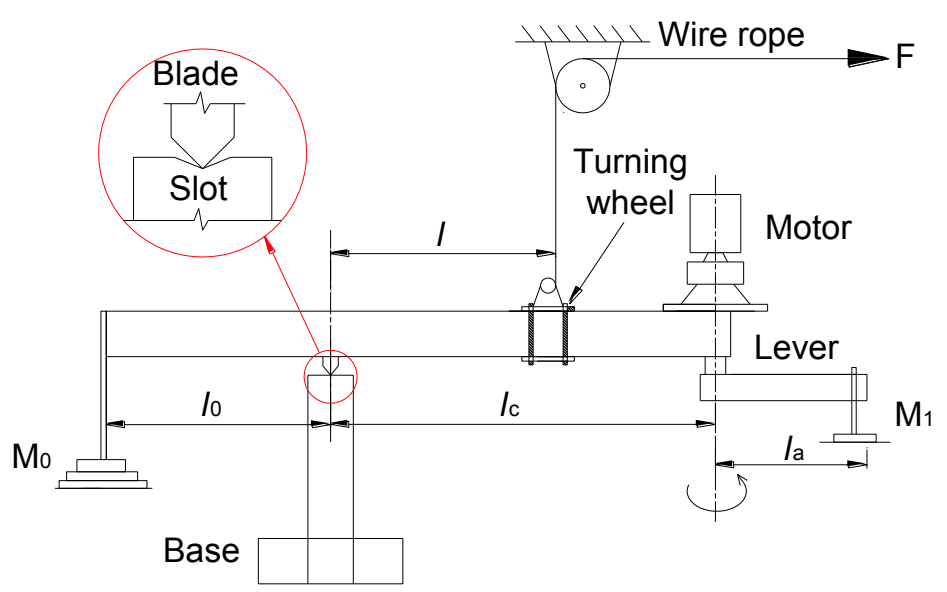

Flat view

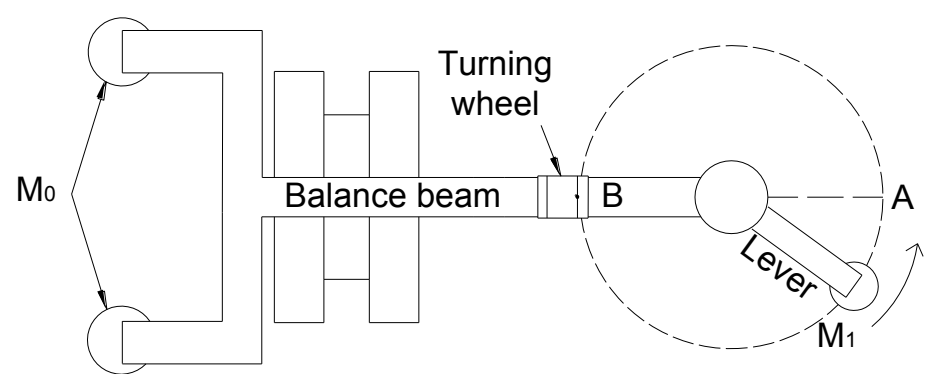

507

(a) Schematic diagram

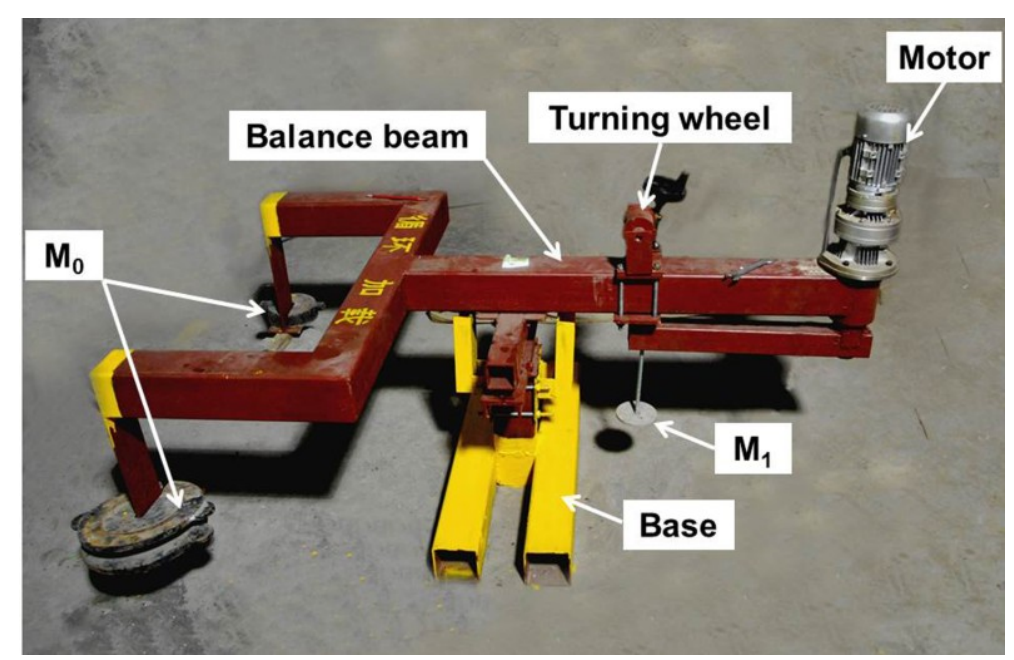

(b) Physical diagram

Fig. 4. The cyclic loading device 


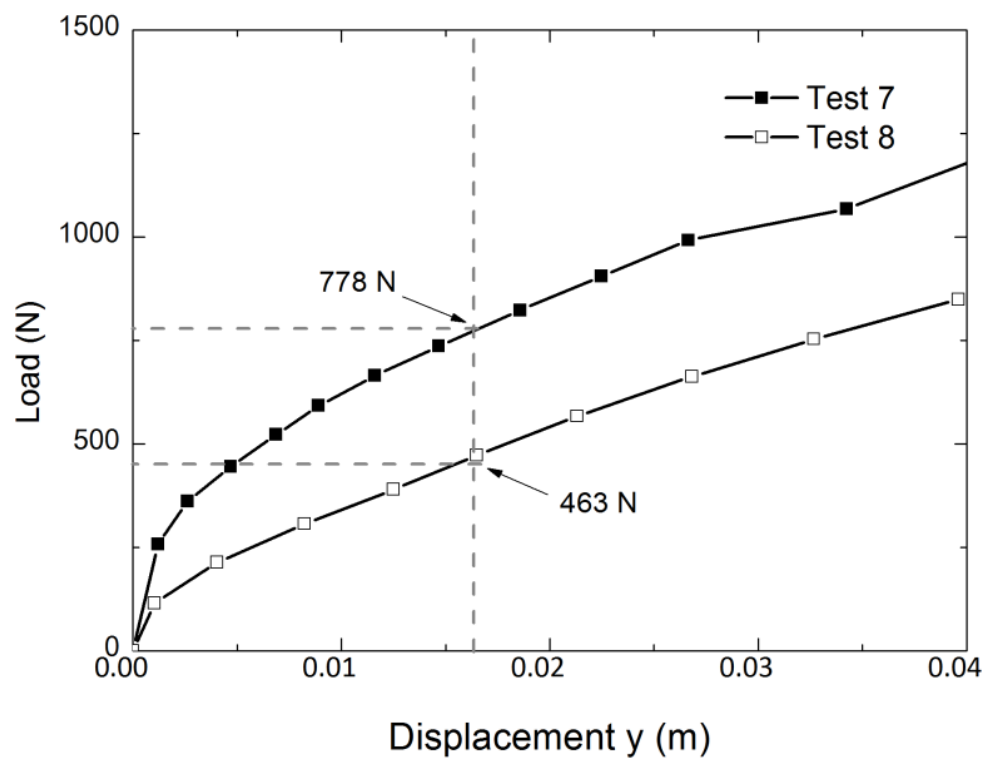

513

514

Fig. 5. Load-displacement curves of Tests 7 and 8

515

516 


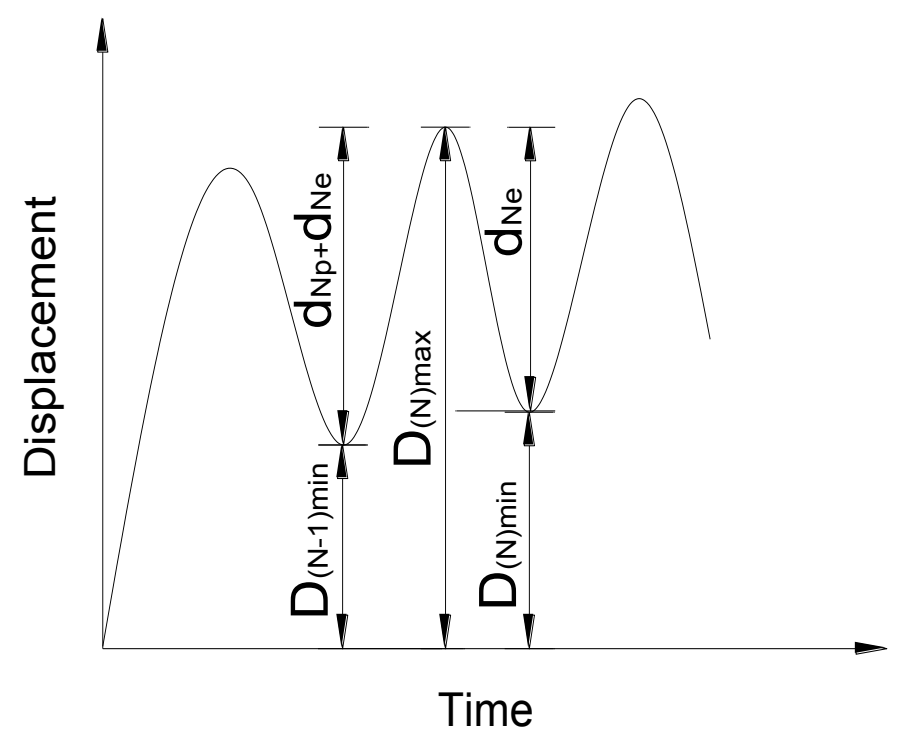

519

Fig. 6. Schematic drawing of the lateral displacement of the pile

520 


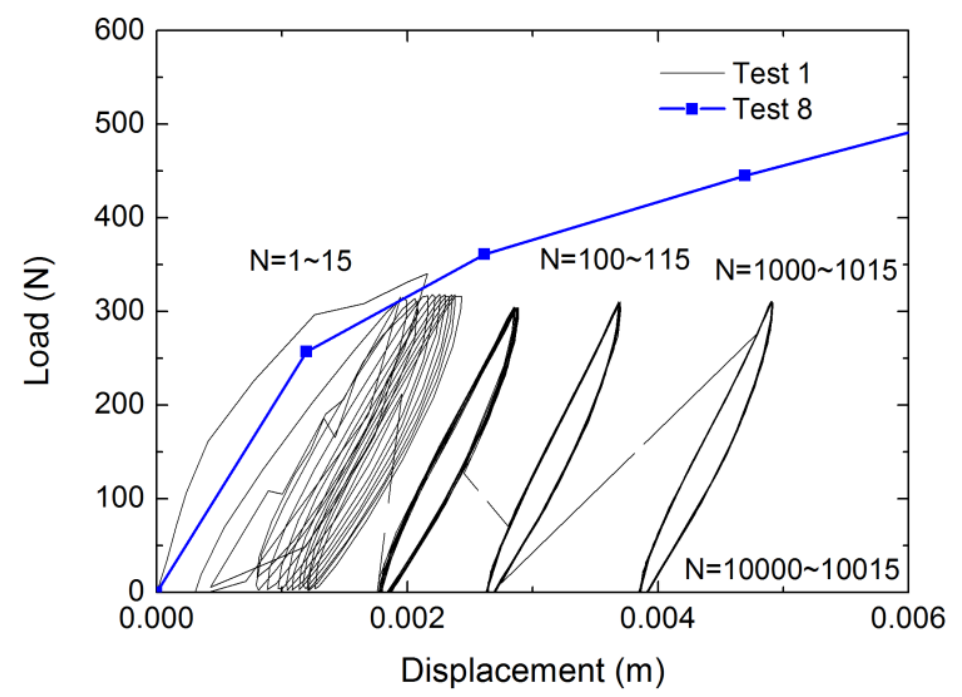

522

523

Fig. 7. Load-displacement curves of Tests 1 and 8

524 


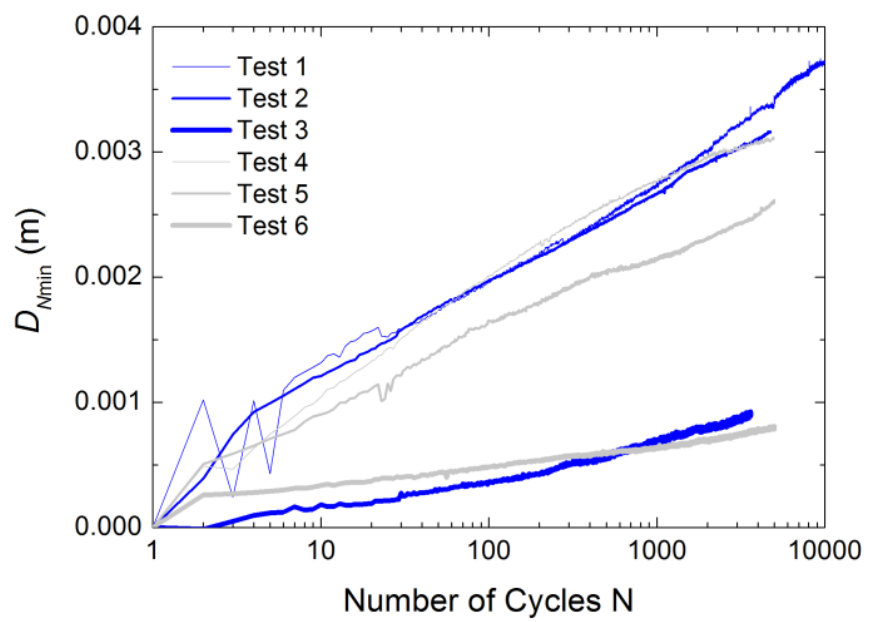

(a) Residual accumulated displacement

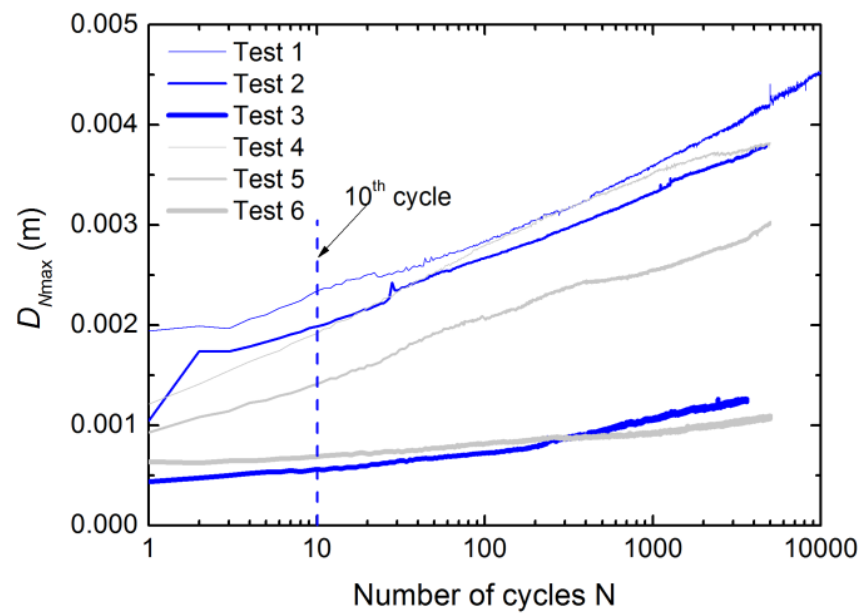

(b) Peak accumulated displacement 


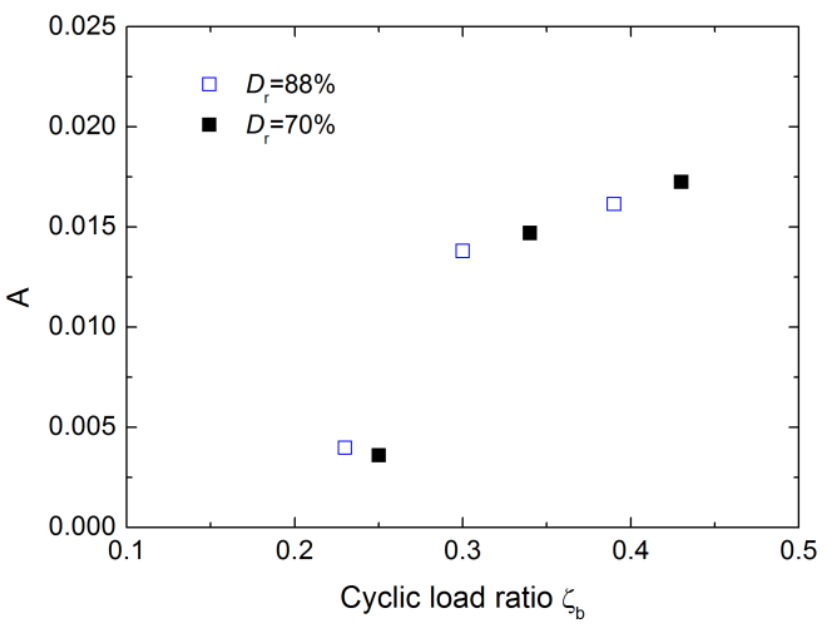

533

534

535

Fig. 9. Values of $A$ 


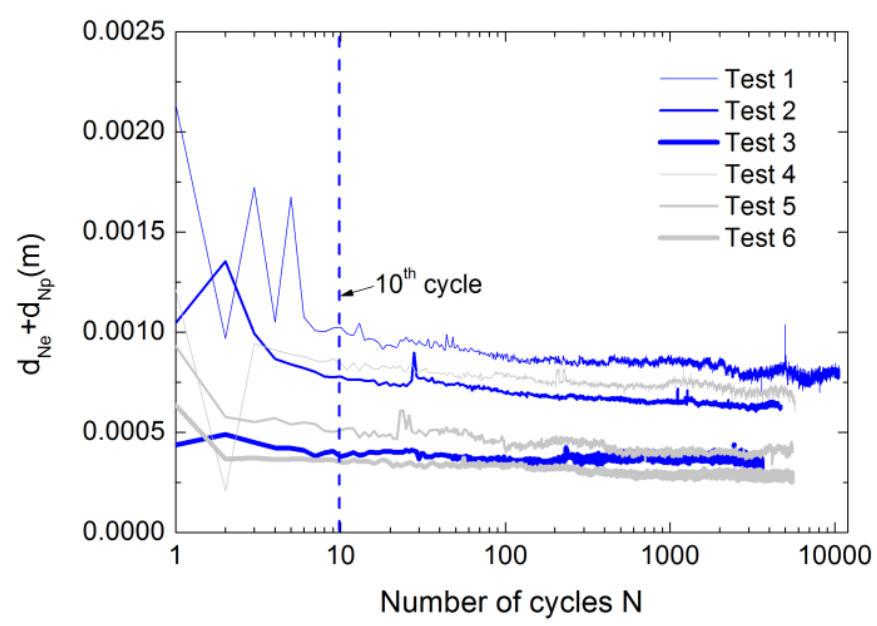

538

539

Fig. 10. Measured total displacement of the pile in each cycle

540 


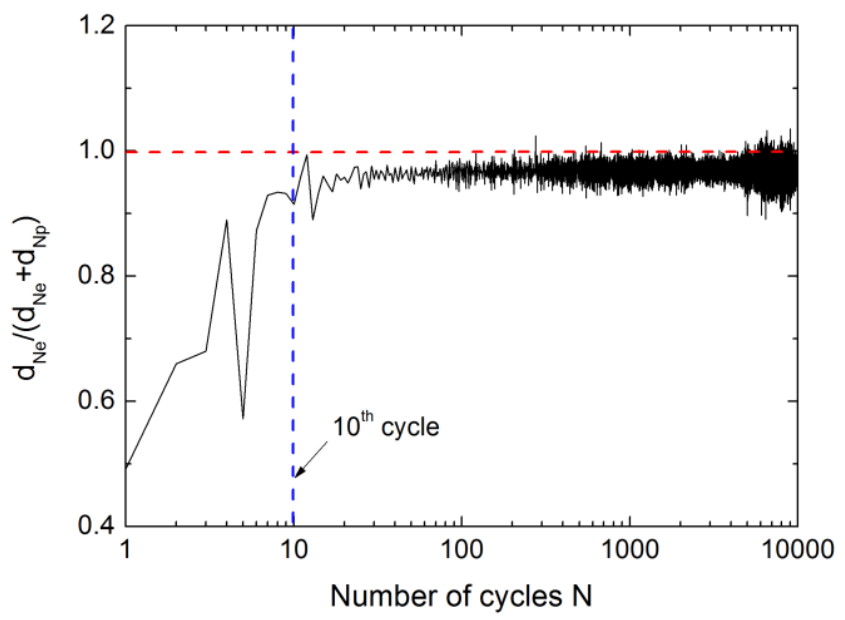

542

543 Fig. 11. Proportion of elastic displacement to total displacement in each cycle (Test 1) 544

545 


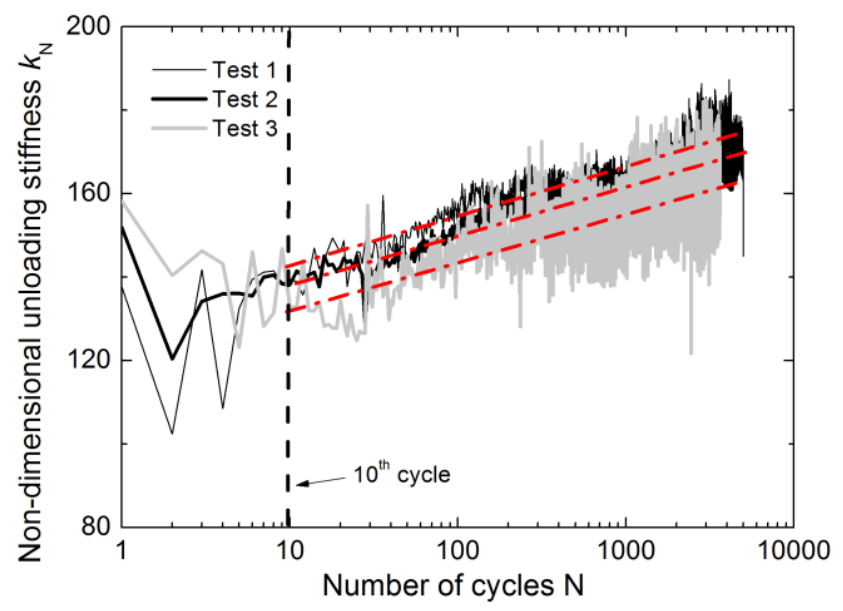

547

548

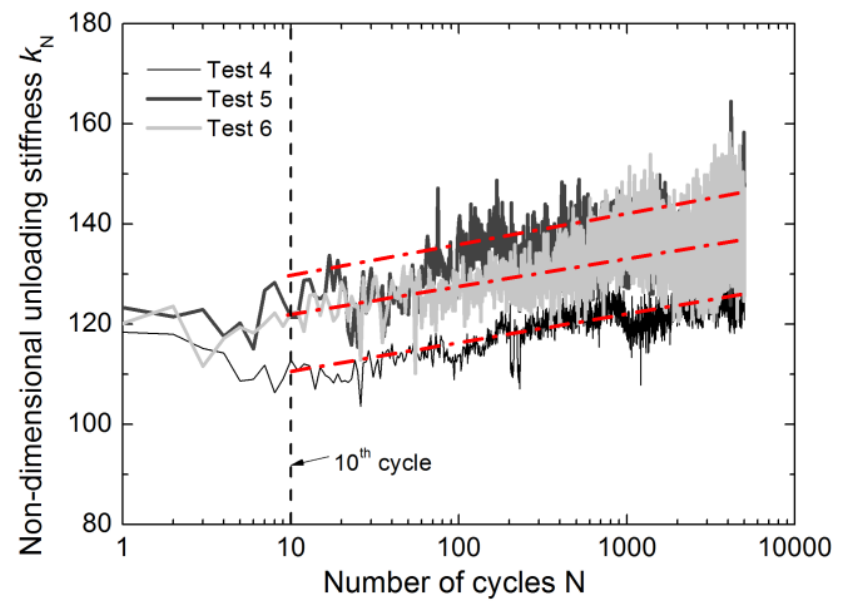

549

550

551

Fig. 12. Non-dimensional unloading stiffness of the pile 


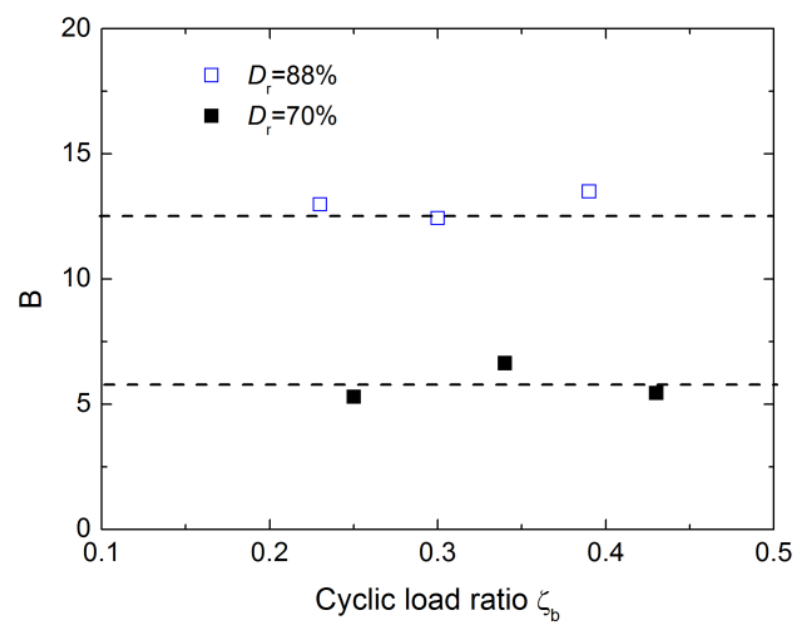

553

Fig. 13. Values of $B$

554

556 


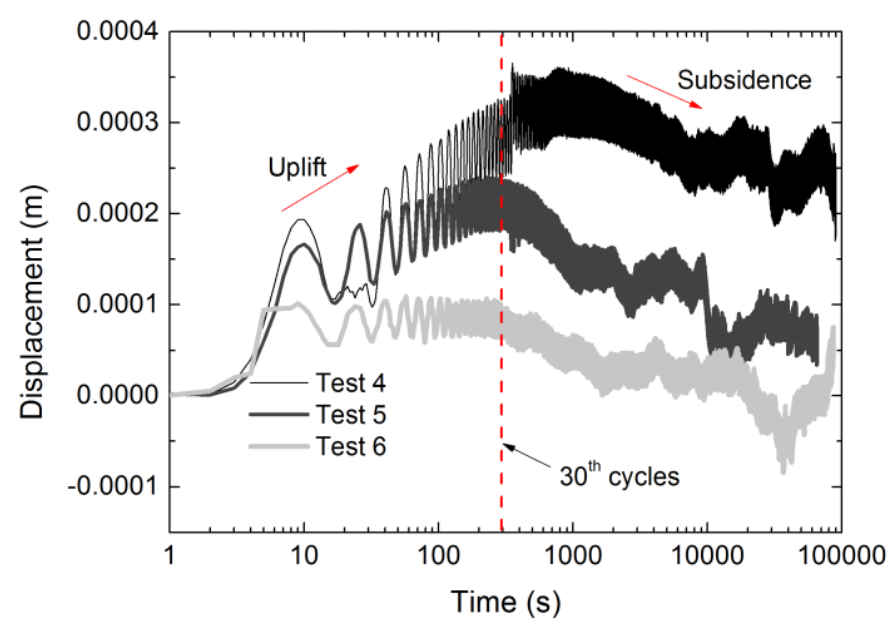

557

558

Fig. 14. Vertical displacement of the soil surface in front of the pile 559 
561

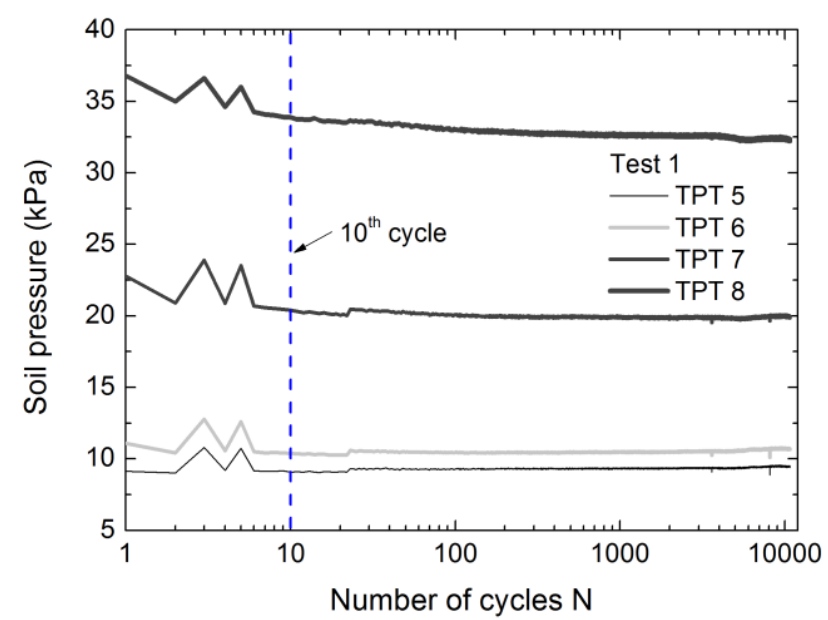

565 Fig. 15. Measured on-pile soil pressures as a function of number of cycles (Test 1)

(a) TPT 1-ТPT 4

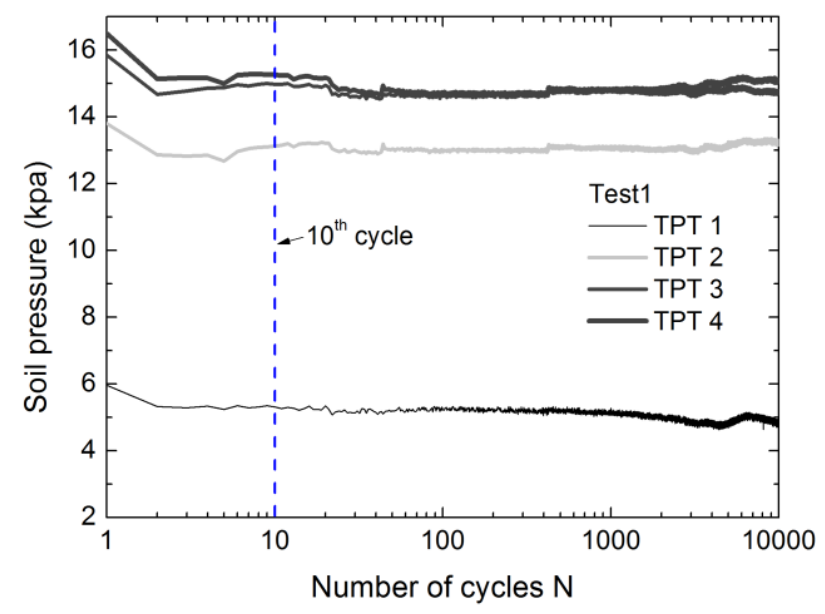

566

567 


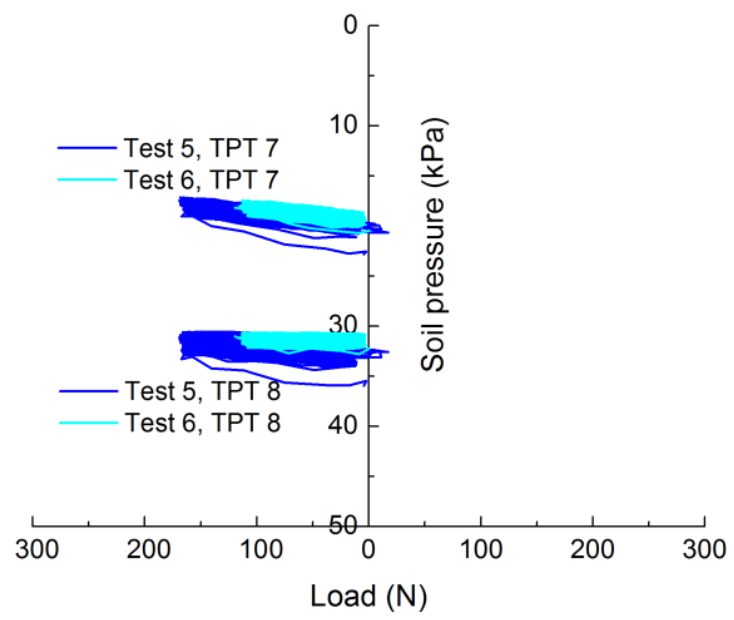

(a) $D_{\mathrm{r}}=88 \%$

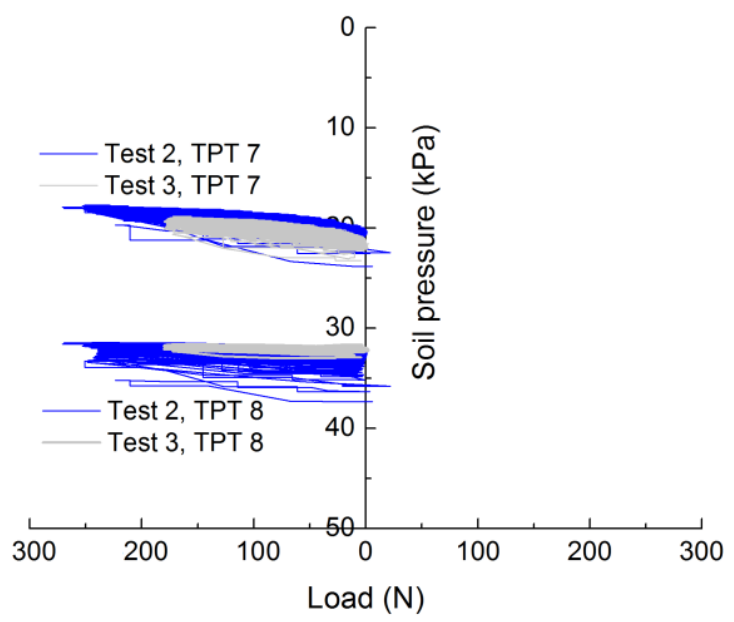

573

(b) $D_{\mathrm{r}}=70 \%$

Fig. 16. Measured on-pile soil pressures of TPTs 7 and 8 


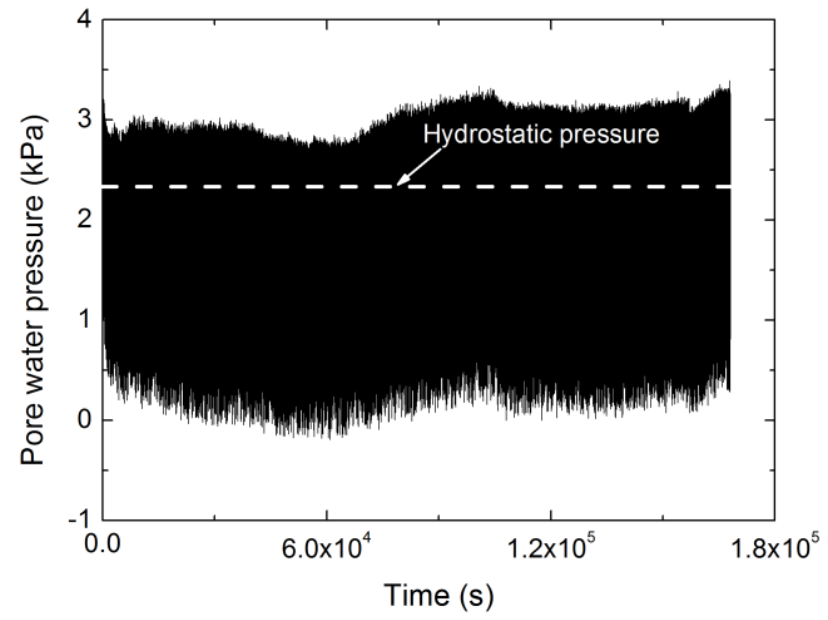

577

578

Fig. 17. Measured pore water pressures (Test 1)

579

580 